Disponível em

http://www.anpad.org.br/rac

RAC, Curitiba, v. 13, Edição Especial, art. 1, p. 1-18, Junho 2009

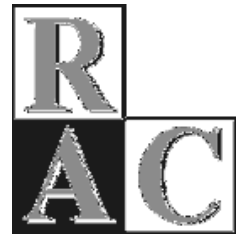

\title{
Estratégias para Compatibilizar Desenvolvimento Econômico e Gestão Ambiental numa Atividade Produtiva Local ${ }^{(1)}$
}

\section{Technology as Strategy to Bring Compatibility between Economic Development and Environmental Management in a Local Productive Activity}

Maria Gracinda Carvalho Teixeira * Doutora em Ciências Ambientais pela University of East Anglia, UEA, Grã-Bretanha. Professora Adjunta na ECSA/UNIGRANRIO, Rio de Janeiro/RJ, Brasil.

Eliane da Silva Bessa

Doutora em Serviço Social pela UFRJ. Professora Adjunta no PROURB/FAU/UFRJ, Rio de Janeiro/RJ, Brasil.

* Endereço: Maria Gracinda Carvalho Teixeira

Universidade do Grande Rio, Escola de Ciências Sociais Aplicadas, Rua da Lapa, 86, $9^{\circ}$ andar, Rio de Janeiro/RJ, 20021-180. E-mail: teixeira.gracinda@unigranrio.edu.br

Copyright (C) 2009 RAC. Todos os direitos, inclusive de tradução, são reservados. É permitido citar parte de artigos sem autorização prévia desde que seja identificada a fonte. 


\section{RESUMO}

O trabalho aqui descrito analisa uma experiência de transferência de conhecimento tecnológico realizada na implantação de um projeto de pesquisa. Compara os princípios e motivações de práticas socioambientais adotadas por uma associação de pescadores artesanais e por organizações industriais, resgatando a relação paradoxal entre racionalidade instrumental e racionalidade de valor quanto à questão ambiental. A análise mostra que organizações industriais e associativas, convivendo no mesmo ambiente, compartilham diferentemente os efeitos das emissões de efluentes industriais que afetam localmente os sistemas ecológicos, a qualidade de vida e a produção econômica, principalmente daqueles que dependem da extração de recursos naturais. Os pesquisadores, fundamentados pelos referenciais teóricos que ajudam a compreender diferentes modos de gestão empresarial e ambiental, adotaram uma metodologia participativa para conduzir a implantação do projeto. Envolveram a comunidade de pescadores em discussões e ações coletivas, que visaram a soluções para questões ambientais locais relacionadas ao desempenho da sua atividade econômica. Os resultados apresentados revelaram que o conhecimento adquirido foi capaz em se transformar, apesar de que fosse de modo conflitante, numa estratégia tecnológica que compatibiliza desenvolvimento econômico e gestão ambiental.

Palavras-chave: estratégia tecnológica; gestão ambiental; desenvolvimento local; transferência de conhecimento.

\section{ABSTRACT}

This work analyzes an experience of transference of technological knowledge which occurred during the development of a research project. It compares the principles and motivations that led to the adoption of socioenvironmental practices by an Association of Fishermen and by industrial organizations, thereby rescuing the paradox relation between instrumental and value rationality and its effect on the environmental question. The analysis shows that industrial and associative organizations, sharing the same environment, share differently the effects industrial effluents have on the local ecological systems, the quality of life and the economic production of those whose lives depend on the extraction of natural resources. The researchers, based on the theoretical references which helped to understand the different forms of environmental management, conducted the project by adopting a participative methodology, led the fishermen's community into discussions and collective actions focusing on solutions to the local environmental questions related to the development of their economic activity. The results demonstrated that their newly acquired knowledge was transformed, albeit in a conflicting way, into a technological strategy which makes economic development and environmental management compatible.

Key words: technological strategy; environmental management; local development; knowledge transference. 


\section{INTRODUÇÃO}

A adoção de tecnologias inovadoras, como estratégia para compatibilizar desenvolvimento econômico e gestão ambiental, é um tema apropriado a estudos que buscam entender como se processa essa relação em atividades produtivas locais realizadas nos países com economias em desenvolvimento, embora poucas experiências dessa natureza se encontrem registradas na literatura concernente.

Centrado nesse entendimento, o foco do presente trabalho incide sobre as motivações empregadas por diferentes organizações produtivas que buscam absorver novas tecnologias capazes de promover o desenvolvimento sustentável de atividades econômicas, evidenciando, assim, as dificuldades estruturais ocorridas tanto na absorção como na implementação dessas tecnologias.

A situação da Baía de Guanabara, RJ, localidade onde ocorreu a experiência analisada, revela quanto a industrialização irrefletida pode trazer riscos consideráveis para a sociedade e para a própria indústria. Por isso, o trabalho provoca uma discussão inicial sobre a relação paradoxal entre a racionalidade instrumental e racionalidade de valor, polemizando a capacidade da indústria de resolver os problemas causados pela sua irracionalidade ambiental.

Durante a última década, houve grande pressão para as empresas reduzirem ou eliminarem emissões, efluentes e desperdícios nas suas operações, atingindo as indústrias de setores chave da economia: petroquímico, automotivo, eletrônico, papel e celulose e alimentício. Independentemente do porte e nível tecnológico organizacional apresentados por essas indústrias, a sua modernização demanda disponibilidade de recursos naturais, estando elas sujeitas à intensidade da competição no mercado, em nível de controle social do produto, ao contexto regulatório, à eficiência na supervisão e na fiscalização e ao custo da certificação, entre outros fatores.

O desafio da modernização tardia nos países em desenvolvimento é encontrar maneiras de redirecionar a sua performance para um caminho onde desenvolvimento econômico e gestão ambiental possam conviver de forma menos conflitante. Os recursos empregados e a escolha do modo como eles são operados conduzem as organizações a um tipo de desenvolvimento possível, e fazem parte do estilo de desenvolvimento que inspira cada nação. Este pensamento norteou as teorias e a compreensão dos padrões de desenvolvimento nos países latino-americanos nos anos 60 e 70 (CEPAL/UNESCO, 1992 como citado em Bielschowsky, 2000; Furtado, 2002) entrando, posteriormente, em descrédito pelo ideário neoliberal. Mais recentemente as idéias de se considerarem as particularidades do desenvolvimento de cada nação estão sendo retomadas, readquirindo importância por agregarem à análise teórica os critérios econômicos, culturais e ecológicos endógenos.

Modelos de desenvolvimento, que têm ressaltado a importância do Estado no planejamento e no controle dos mecanismos legais, sugerem um papel menos prioritário do Estado na regulação do mercado e mais de articulador de mecanismos de alavancagem, como, por exemplo, de iniciativas organizacionais que representem comunidades produtivas, onde a força da cidadania e da legislação ainda se encontram fragilizadas.

As escolhas tecnológicas na indústria brasileira do pescado representam uma boa ilustração dessa tendência. De modo geral, o abastecimento no país de produtos oriundos da pesca provém de cooperativas e associações que têm transformado a extração manual dos bancos naturais, ao longo do litoral brasileiro, em atividade econômica vital para um número expressivo de populações costeiras.

Nesse estudo, onde diferentes organizações produtivas compartilham do mesmo ambiente - as águas da Baía de Guanabara - são realizadas atividades econômicas conflitantes entre si, como a extração de recursos naturais e do pescado, por um lado ${ }^{(2)}$, e a emissão de efluentes químicos pelas indústrias, por outro $^{(3)}$. 
O projeto de transferência de conhecimento em questão, na experiência analisada por esse trabalho, é visto como um vetor de mudanças do quadro socioambiental sombrio em que se encontra a pesca artesanal na região, porquanto, ao promover um processo de modernização industrial, acaba pressionando indiretamente as indústrias sardinheiras a se comprometerem, também, aos padrões de exigências ambientais das suas atividades produtivas.

Nesta perspectiva, o trabalho procura apontar as evidências sobre os princípios e motivações para a adoção de práticas socioambientais nas indústrias e na associação de pescadores artesanais, e que medidas estão adotando essas organizações para superarem as dificuldades e buscarem um convívio mais harmonioso entre o desenvolvimento econômico e a gestão ambiental relacionado às atividades produtivas.

\section{A RACIONALIZAÇÃo Industrial é CAPAZ de Resolver sua IrRACIONALIDADE AMBIENTAL?}

A Sociologia do Desenvolvimento tem, de certa forma, negligenciado os limites ambientais (Redclift, 1984). Na verdade, a Teoria Social tem demonstrado pouco interesse pela relação entre racionalidade econômica e meio ambiente, apesar de, ainda na década de 70, Catton e Dunlap (1978) terem chamado atenção para sua importância. Todavia, a análise das questões ambientais enquadra-se perfeitamente na problemática da racionalização ocidental, estudada, há quase um século, por Max Weber. Embora ele mesmo não tenha examinado essa relação em detalhe, Albrow (1990) mostra que a análise de Weber pode ser valiosa nos dias atuais, por demonstrar que a racionalidade ocidental se tem transformado tanto em estruturação rígida da vida moderna, quanto em tendências irracionais, ou seja, Weber analisa a relação paradoxal entre racionalização e irracionalidade, que pode ser útil no entendimento do "conflito entre 'racionalidade instrumental' e 'racionalidade de valor' acerca das relações sociais com a natureza" (Albrow, 1990, pp. 145-284).

A modernidade sempre acreditou que as ações humanas são capazes de domesticar, manipular e reconstruir a natureza, numa linha de argumentação - ainda preponderante na mídia, na ciência e nos discursos de empresários e de autoridades públicas - que legitima uma exploração da natureza desprovida de responsabilidades, no que tange às externalidades da atividade econômica. A expressão mais atual desta argumentação é a crença de que futuras descobertas tecnológicas irão reparar danos presentes. O paradoxo weberiano, porém, nos confronta com um perigoso dilema: a tecnologia dá conta dos danos ambientais causados pela própria tecnologia?

A premissa da "plasticidade da natureza" (Murphy, 1994, pp. 3-42) surgiu com a própria modernidade. Diferenciando-se do pensamento malthusiano, anterior ao iluminismo, ela nega a complexidade da natureza e supõe que a vontade dos seres humanos possa reconstruir sua relação com o ambiente natural. No entanto, a própria ciência moderna acabou por mostrar que a natureza é muito mais complexa e resistente à manipulação humana do que se pensava, sendo capaz de reagir, de forma devastadora e desafiando o próprio conhecimento humano, diante de reações ecologicamente incontroláveis (Perrow, 1984). É bem verdade que, também, a teoria malthusiana vem sendo refutada. A relação entre sociedade e natureza mostrou-se historicamente muito mais maleável do que a apregoada pela corrente malthusiana, de que os recursos naturais seriam insuficientes diante do crescimento populacional. De um lado, os meios de subsistência cresceram mais rápidos do que as populações; de outro, estas conseguiram limitar o seu crescimento, por meio do controle da natalidade. Nos países mais industrializados, em particular, apesar de um aumento da expectativa de vida, a população declinaria drasticamente, se não houvesse imigração (Murphy, 1994). Ainda assim, neomalthusianismo e plasticidade da natureza competem atualmente como suportes teóricos em prol de uma reavaliação, para menos, dos danos ambientais causados pelo crescimento industrial.

No extremo oposto da Teoria Social estão autores que acentuam o lado irracional da modernidade industrial. Argumentam que, sob pressão da concorrência no mercado, o empresário se vê obrigado a 
incorporar, nos processos de decisão, uma racionalidade puramente econômica, em cujos cálculos de custos a natureza é destituída de qualquer valor. Em outras palavras, a economia de mercado se apóia num modelo de desenvolvimento que privilegia e sustenta uma racionalidade econômica ambientalmente inadequada (Griefahn, 1993). Alguns autores vão além, denunciando o surgimento de uma elite industrial que se julga inatingível pela controvérsia ambiental (Parker \& Martin, 1993).

Uma terceira corrente teórica, mais diretamente influenciada pelas idéias de Weber, confere aos riscos ambientais e tecnológicos um lugar central na Teoria Social. Ela julga que os riscos e as incertezas gerados por um desenvolvimento irrefletido da técnica e da economia, fizeram com que a modernização se tenha transformado em problema para a própria modernidade.

Assim, como ressalta Beck (1994), a sociedade industrial entrou numa fase de modernização reflexiva, na qual ela se tornou tema de discussão para si mesma. Onde antes havia uma sociedade baseada no princípio da escassez e caracterizada por sua capacidade de produzir e distribuir desigualmente as riquezas, há agora uma sociedade saturada, que gera incertezas e efeitos cada vez mais imprevisíveis, ou seja, a sociedade industrial transformou-se numa sociedade de risco, que produz e distribui, desigualmente, os riscos ambientais e sociais. Portanto, os riscos trazidos pela modernidade constituem o fator mais importante para compreender as características, os limites e as transformações dessa própria sociedade. A crise ecológica expressa, na verdade, uma crise institucional profunda da própria sociedade industrial. As decisões precisam ser tomadas sob novas regras e bases, que aceitam o diálogo e reconhecem como inevitáveis a ambigüidade e a ambivalência dos processos sociais (Beck, 1994).

O paradoxo teórico vem sendo enfrentado, na prática, por uma grande expansão, em inúmeros países, da legislação encarregada de controlar as atividades poluidoras e pela correspondente reação do setor empresarial às normas de conduta voluntária. Dentre estas, a que tem provado maior eficácia é a série ISO 14000, que propõe um sistema fechado de gestão e de identificação dos seus próprios parâmetros de monitoramento e melhoria. Apesar das dúvidas que tal procedimento possa suscitar, quanto a um efetivo aperfeiçoamento do desempenho ambiental da indústria, não é menos verdade que também os mecanismos legais, baseados em conceitos de comando e controle, ainda precisam de muitos ajustes, até que venham a provocar um envolvimento espontâneo, por meio do automonitoramento e autocontrole das atividades econômicas poluidoras. Portanto, é conveniente que mecanismos de comando e controle de gestão ambiental sejam utilizados conjuntamente com uma conduta empresarial mais responsável e comprometida com as condições ambientais adequadas para o bem-estar social.

A auditoria ambiental, por exemplo, foi inicialmente adotada pelas empresas com o único intuito de prevenir acidentes e infrações à legislação ambiental; mais tarde, porém, foi integrada aos sistemas de gestão dos processos de produção. Tendo precedido os sistemas de gestão ambiental das organizações, ela acabou por ser inserida na gestão responsável, como mecanismo de auto-regulação. Converteu-se, assim, em poderoso instrumento para avaliação permanente de dados e parâmetros de desempenho ambiental das organizações industriais, passando a constituir-se em importante auxílio à missão do poder público de garantir à sociedade seu direito a um meio ambiente saudável.

Na perspectiva da empresa, a gestão ambiental pode ser encarada como uma função gerencial global que trata, determina e implementa uma política de meio ambiente na organização. Com ela, a gestão da empresa passa a incluir, em seus planos e metas, as externalidades advindas de sua atividade. $\mathrm{O}$ setor produtivo absorve a responsabilidade pela melhoria das condições da sua área de atuação, não somente como resultado de pressões exercidas pelos agentes sociais e instituições, mas também como código de conduta voluntário, criado geralmente por instituições que congregam representantes de vários setores industriais. 


\section{GESTÃo AMBIENTAL DA INDÚSTRIA NO BRASIL}

O controle dos riscos ambientais do crescimento econômico assume contornos bem específicos nos países em desenvolvimento. O Brasil dispõe de legislação ambiental bastante moderna. A fiscalização, porém, é insuficiente. Portanto, as normas voluntárias podem constituir uma contribuição significativa para a melhoria da qualidade ambiental. O país é membro fundador da ISO, sendo nela representado pela Associação Brasileira de Normas Técnicas $[\mathrm{ABNT}]^{(4)}$. Para o caso específico da normalização ambiental, foi criado em 1994 o Grupo de Apoio à Normalização Ambiental [GANA], resultante de iniciativa de 36 empresas, além de associações, universidades e entidades representativas de setores econômicos e técnicos considerados importantes no país. O GANA contribuiu para a elaboração da série ISO 14000, apresentando as particularidades relacionadas ao meio ambiente de um país tropical e de uma economia em desenvolvimento. Nas reuniões anuais do Comitê Técnico de Gestão Ambiental da ISO, o Brasil esteve sempre entre as três maiores comitivas. Mais tarde, o GANA foi substituído pelo Comitê Brasileiro de Gestão Ambiental, que avalia as revisões das normas com novas propostas.

O gráfico a seguir indica as motivações daqueles que chegaram a implantar práticas ambientais de qualquer tipo, segundo pesquisa realizada pela Confederação Nacional da Indústria [CNI]. Observa-se que a proporção de respostas que atribuem a adoção de práticas de gestão ambiental à própria política da empresa é praticamente equivalente à que confirma a força das exigências legais.

\section{Figura 1: Razões para Adoção de Práticas de Gestão Ambiental por Empresas Industriais Brasileiras}

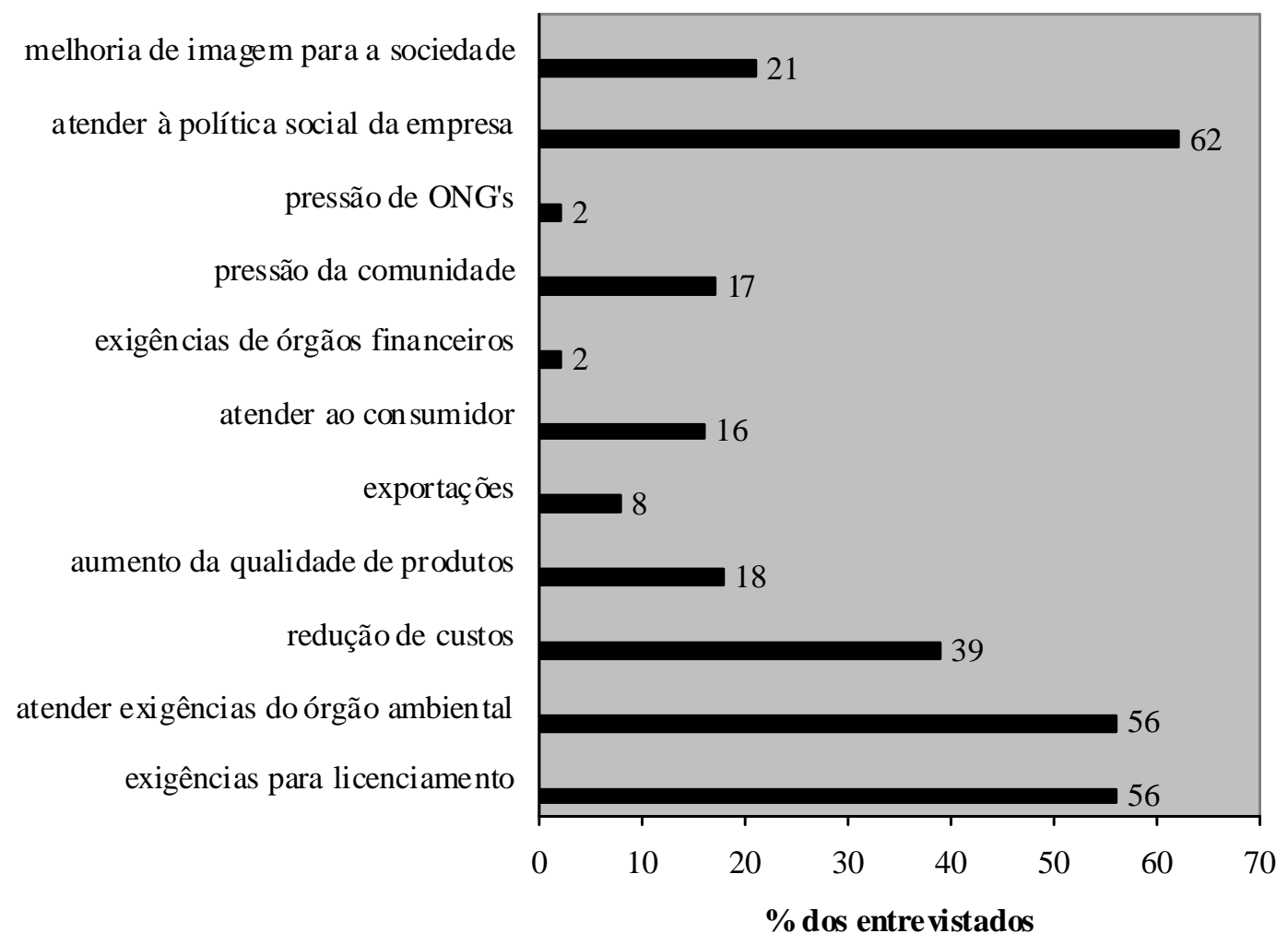

Fonte: dados adaptados da pesquisa da Confederação Nacional da Indústria/Banco Nacional do Desenvolvimento Econômico e Social/Serviço Brasileiro de Apoio às Micro e Pequenas Empresas [CNI/BNDES/ SEBRAE] (1998, pp. 23-24). 
Como foi dito anteriormente neste trabalho, as opções tecnológicas das empresas podem ser as mais diversas. A escolha daquela que resulta em desenvolvimento sustentável depende de fatores tais como: a escassez de recursos naturais, mercados mais competitivos, pressão da sociedade civil, existência de mecanismos de fiscalização e, finalmente, o próprio custo financeiro para implantação e certificação da norma ISO 14000. Isso ajuda a entender melhor os indicadores apontados no estudo acima.

Em países como a Alemanha, por exemplo, a cooperação do empresariado industrial com as políticas de governo tem resultado numa reorganização estrutural da indústria. As autoridades oferecem um prêmio aos produtos e serviços ambientalmente adequados (Griefahn, 1993). A autora explica que o princípio de punir quem polui é substituído pelo princípio de premiar quem não polui. Porém, no caso das economias em desenvolvimento, os fatores que influenciam a capacidade do país em fazer negócios com os países mais industrializados são, muitas vezes, determinantes para a adoção de práticas de gestão ambiental. Quando a legislação destes países é mais flexível do que a dos países de origem das empresas multinacionais, estas podem optar por transferir suas operações para filiais nos países em desenvolvimento. Assim, as barreiras tarifárias, as sobretaxas, os códigos empresariais e os selos verdes, que regem o comércio internacional, nesse caso passam a assumir caráter complementar, ao invés de caráter determinante, nos países de economia periférica.

Assim como as empresas dos países de economia mais avançada, as empresas brasileiras começam lentamente a absorver o discurso de que o crescimento econômico e proteção ambiental devem estar obrigatoriamente associados. Por essa razão, há uma procura de empresas que querem diferenciar-se e, portanto, participam da corrida à certificação que agrega valor ao produto, pois representa um selo de confiança no sistema de gestão implementado pelas empresas. Os certificados mais procurados são, além da ISO 14000, os da série ISO 9000, que se referem à gestão ambiental baseada no gerenciamento da qualidade total (Vinha, 2003).

A demora das organizações brasileiras em internalizar o conceito de desenvolvimento sustentável deve-se a diversos fatores. Um deles é o fato de as trajetórias seguidas pelas diferentes empresas de diferentes setores diferirem significativamente. Isso se deve também à concepção, que predominou durante décadas, de que a preservação do meio ambiente e o lucro eram antagônicos. Essa concepção se refletiu nas organizações de todos os portes e setores. Refutar essa concepção tem sido um processo lento, tendo-se chegado, em alguns países, na incorporação da visão de stakeholders $^{(5)}$ nas novas estratégias de desenvolvimento.

Como esclarece Vinha (2003), com o surgimento do Social Accountability, 8000 [SA 8000], que é certificado social de reconhecimento internacional, administrado pelo Council on Economic Priorities Accreditation Agency [CEPAA], uma nova demanda passa a compor o quadro de exigências às empresas. O SA 8000, entre outros aspectos, verifica as condições de trabalho em toda a cadeia produtiva. Esse certificado abriu caminhos para o surgimento de políticas de Responsabilidade Social Corporativa nas empresas, obrigando-as ao empenho de envolverem seus stakeholders e manterem relacionamentos produtivos de longo prazo

Vinha (2003, p. 178), ao citar Altvater (2000), ressalta que hoje agregam a esses stakeholders as vítimas, reais e potenciais, da poluição ambiental. Com base nesse princípio, Vinha explica que o principal desafio das organizações é aprender a lidar com os anseios e as expectativas das populações locais, com a pressão do movimento ambientalista e com o poder de barganha dos órgãos públicos, principalmente quando essas organizações, de pequeno, médio ou grande porte, operam em áreas ambientalmente sensíveis.

\section{Desafios Ambientais Na Atividade Produtiva Local}

No Brasil, há poucas experiências registradas de incremento da atividade pesqueira, particularmente de cultivo de mexilhão, que manifestam preocupação com a preservação ambiental, com a introdução 
de técnicas inovadoras e com foco no aprendizado coletivo, apesar da comprovada melhoria de renda alcançada por grupos que se comprometeram com essas novas estratégias produtivas locais ${ }^{(6)}$.

Da mesma forma, poucos são os registros desse tipo de experiência incremental na literatura concernente ao tema. Um dos casos similares ao presente estudo refere-se à atividade de cultivo de mexilhão na Galícia. Nesse caso a estratégia apontada como inovadora recai sobre a capacidade do grupo de gerar novos produtos, processos, métodos ou organizações que implicam ganhos tecnológicos, aumento da competitividade e permanência do produto, sem esquecer de ressaltar, entre outros fatores, o peso do conhecimento prático e da criatividade na implementação de melhorias alcançadas pelos grupos sociais que desenvolvem a atividade econômica em questão (Rodríguez, 2007).

A atividade de mitilicultura no Brasil, em geral, se desenvolve por meio da extração ocorrida em bancos naturais, embora já existam experiências como a relatada neste estudo que utilizam métodos e técnicas considerados inovativos em relação à forma extrativista. Devido ao seu valor econômico, tem havido aumento da exploração e comercialização de mexilhões por diversas populações litorâneas, de forma indiscriminada, não havendo ainda estatísticas oficiais em relação à quantidade de mexilhões extraída dos costões, seu habitat natural.

As diretrizes ambientais do governo brasileiro para o Setor Pesqueiro, estabelecidas pela Secretaria de Pesca e Aqüicultura do governo federal em 2003, consideram que a extração de mexilhões no país é caracterizada por forte dualidade: "ou utiliza os mais rudimentares mecanismos para apoio à produção, ou concorre a uma infra-estrutura comparável àquelas do primeiro mundo" (Ministério do Meio Ambiente [MMA], dos Recursos Hídricos e da Amazônia Legal, 1997, p. 18).

Essa dualidade organizacional reflete as opções políticas oferecidas ao setor pesqueiro pelo governo federal, durante as últimas três décadas. Como enfatiza o entrevistado, "embora no discurso oficial a prioridade tenha sido a pesca artesanal, investimentos têm sido sempre canalizados para a pesca industrial" (M. de Lima, presidente da Associação Livre dos Maricultores de Jurujuba [ALMARJ], entrevista pessoal, 12 de dezembro, 2002).

Com a criação da Secretaria de Pesca e Aqüicultura do governo federal, espera-se que o quadro venha a se modificar. Como enfatiza o assessor técnico desta secretaria, "desde a sua inauguração têm sido focalizadas as demandas locais, através de eventos que visam congregar os profissionais da pesca artesanal, com fins de promover mudanças estruturais" (J. Avelar, entrevista pessoal, 7 de janeiro, 2003).

Ainda não se evidenciam os resultados decorrentes dessa medida, permanecendo a mesma falta de infra-estrutura e de suporte financeiro, principalmente no que diz respeito ao apoio do governo federal. A situação é mais diversificada naquelas atividades cuja operacionalização foi transferida aos governos estaduais e municipais, ou às entidades de classe dos produtores. Há algumas experiências bem sucedidas, mas o nível de alcance de seus objetivos ainda é pouco visível.

\section{A BaÍA de Guanabara, Atores e TRANSFORMAÇõeS}

Segundo Amador (1997), o poder público, diretamente ou por meio de concessões, foi o principal agente responsável pelo processo de destruição física que ocorre na Baía de Guanabara. Tal processo, segundo o autor, iniciou-se com a extração do pau-brasil, passando por aterros, instalação de pólos industriais e urbanísticos desprovidos de planejamento e de preocupação com o meio ambiente, práticas de um modelo de desenvolvimento econômico de orientação urbano-industrial, gerando toda a sorte de poluição. 
A população residente em torno da Baía de Guanabara chega a ultrapassar 7 milhões de habitantes, o que significa praticamente dois terços da população da região metropolitana do Rio de Janeiro. Desse total, $80 \%$ concentra-se nas áreas urbanas dos distritos municipais centrais. A densidade populacional nessa região é uma das mais altas do país, alcançando 5,3 habitantes por quilômetro quadrado.

Estudos de Amador (1997, pp. 10-30) confirmam que "a área física da Baía de Guanabara perdeu, desde o ano de 1500, ano da chegada dos portugueses ao Brasil, 80 quilômetros quadrados". Suas previsões para o ano 2025 são de que os atuais 381 quilômetros quadrados de Baía de Guanabara sofrerão uma perda adicional de 60 quilômetros quadrados, se nenhuma medida preventiva for tomada. Sua pesquisa sobre a evolução geomorfológica da Baía de Guanabara descreve-a como um conjunto de ecossistemas em processo de degradação, em boa parte provocada pela ocupação desordenada. Os níveis de assoreamento e erosão são alarmantes, bem como o desaparecimento de manguezais que sustentam sua fauna e flora.

A Secretaria de Obras e Serviços Públicos do Estado do Rio de Janeiro informou, por ocasião da realização da pesquisa, que existem mais de 6000 indústrias em volta da baía, mas o impacto ambiental mais significante é causado principalmente por 55 destas indústrias. Entre elas estão 6 indústrias de sardinha, vizinhas à comunidade de Jurujuba, onde fica a tradicional Colônia de Pescadores e a Vila de maricultores. Outra fonte de poluição é representada pelas unidades da empresa Petrobrás, sobretudo a Refinaria Duque de Caxias e terminais de petróleo. Existem dois portos comerciais, o de Niterói e o do Rio de Janeiro. Os 2.000 postos de serviços, incluindo postos de gasolina, 32 estaleiros, vazadouros de lixo (em especial, o Aterro Metropolitano de Gramacho) e indústrias de construção civil também têm a sua parcela de contribuição na poluição da baía.

Além dos efluentes líquidos das indústrias, a Fundação Estadual de Engenharia do Meio Ambiente [FEEMA, 2000], destaca a poluição doméstica como um dos grandes fatores de poluição da baía. Somada a isso a emissão de óleos e os resíduos sólidos urbanos, sem contar com o lançamento de 3.000 toneladas lixo por dia no aterro sanitário às margens da baía, todos juntos contribuem para agravar ainda mais o quadro de degradação ${ }^{(7)}$.

No conjunto das 55 indústrias chamadas prioritárias pelo Programa de Despoluição da Baía de Guanabara do Governo Estadual, 11 pertencem à tipologia alimentícia; as 6 do ramo de pescado são vizinhas da Colônia de Pescadores de Jurujuba ${ }^{(8)}$. Estudo de Scheeffer (2002) sobre as indústrias que poluem a Baía de Guanabara comprovou que, dentre as indústrias de tipologia alimentícia, são as do pescado as que apresentam as maiores quantidades de poluentes químicos e orgânicos. Todas são consideradas de alto potencial poluidor. Seus despejos industriais provêm das etapas de lavagem e descamação do peixe, evisceração e lavagens da área de produção. Quanto aos efluentes líquidos destas empresas, duas delas não possuem nenhum tipo de sistema de tratamento adequado e apenas uma se enquadra na faixa mais restrita de acordo com os parâmetros estabelecidos pela FEEMA. Porém, se implantarem um sistema adequado de tratamento, é possível que consigam adequar-se aos limites permitidos, de acordo com as normas estabelecidas por esse órgão público de fiscalização do meio ambiente (Scheeffer, 2002).

Dentro da visão ampliada de stakeholder de Altvater (2000 como citado em Vinha, 2003), pode ocorrer um aumento das possibilidades de reversão do ambiente, devido ao estímulo à participação de uma população antes inerte.

Desde 1988, representantes da sociedade civil se vêm manifestando sobre a poluição na Baía de Guanabara. Em 1990 surgiu o Movimento Baía Viva, formado por ecologistas, pesquisadores, parlamentares e lideranças de diversos bairros. Vários ex-integrantes do movimento são hoje parlamentares que defendem a causa ambiental (Assembléia Legislativa do Estado do Rio de Janeiro [ALERJ], 1998). Em 1996, firmaram o Pacto pela Despoluição da Baía de Guanabara, comprometendo-se publicamente a usar seus mandatos para lutarem pela recuperação da Baía.

Para a representante do Movimento Baía Viva, "a mais importante vitória sob pressão da sociedade foi a criação, pelo governo estadual, em 1994, de um grande programa de despoluição com o objetivo 
de promover a instalação da rede, inexistente, de esgotos dos vários municípios banhados pela baía" (S. Herculano, entrevista pessoal, 13 de junho, 2002).

Contudo, há dúvidas quanto à eficiência das estações de tratamento planejadas. Se estas não apresentarem bom desempenho, a poluição se concentrará, agravando a situação da baía. Um fórum de acompanhamento, criado por lei em 1995, determina a participação efetiva da sociedade civil na fiscalização das obras e da aplicação do dinheiro público.

Outro sinal de mudança é uma lei estadual de 1991 que obriga as empresas de elevado potencial poluidor a procederem a auditorias ambientais anuais, realizadas por equipes técnicas independentes e pagas pelas empresas poluidoras. Tais auditorias deveriam funcionar como autêntico monitoramento ambiental a custo zero para o Estado. No entanto, são poucas as empresas que já cumpriram a lei, devido à alegação dos altos custos relativos ao processo de auditoria.

Os agentes poluidores acabam atingindo a Colônia de Pesca Z-8, criada em 1921, e hoje com cerca de 10.000 pescadores cadastrados. Em 1994, pescadores da Colônia de Pesca Z-8 buscaram apoio técnico de pesquisadores, para manifestarem sua preocupação com a interferência da poluição na pesca artesanal: o lixo flutuante prejudica suas operações e o que está no fundo da baía vem misturar-se ao pescado, dentro das redes. A partir desse contato, uma sucessão de ações foi desencadeada, como, por exemplo, a coleta de lixo doméstico nos morros, onde os caminhões da Companhia de Limpeza Urbana não têm acesso, evitando que ele seja carregado para a baía pelas enxurradas. Uma das ações, executada por moradores voluntários, com apoio de ONG's, chegou a envolver 3000 pescadores. Outro exemplo é um projeto para processar os resíduos da própria produção dos pescadores, que são as cascas dos mariscos que cultivam, evitando assim o assoreamento que a sua atividade produz nas cercanias da colônia de pesca (Bessa, d'Avignon, Valle, \& Teixeira, 2004).

Mais recentemente, os pescadores vêm tentando reativar junto aos órgãos públicos um antigo projeto de melhorias urbanísticas para o bairro onde residem, o que contribuiria para mudar, de modo significativo, a qualidade das águas da baía, uma vez que o projeto inclui obras de saneamento ambiental no bairro $^{(9)}$.

\section{O Projeto da AsSociaÇão de MARICULTORES de JURUjuba}

No contexto, já mencionado, da falta de apoio público à pesca artesanal criou-se a Associação Livre dos Maricultores de Jurujuba [ALMARJ], em 1992, situada no bairro do mesmo nome, às margens da Baía de Guanabara. A área onde se situam os maricultores inicialmente abrigava apenas uma pequena aldeia de pescadores. Aos poucos o bairro foi crescendo, porém, de forma desordenada. E, mesmo não ocorrendo uma alta densidade populacional nos bairros vizinhos, eram inevitáveis os danos causados ao meio ambiente em razão da ausência total de infra-estrutura urbana.

A situação atual de Jurujuba, bairro do Município de Niterói, precariamente provido de infraestrutura urbana, apresenta um decréscimo populacional ocasionado, em parte, pelos problemas ambientais da baía, os quais têm expulsado os pescadores para outras atividades econômicas. No entanto, vale observar que o mesmo não acontece com outras localidades do município, em termos de população, como demonstrado na tabela a seguir. Essa emigração só reforça a idéia de que a permanência de uma população no seu local de origem, só se sustenta se ocorrerem os meios que assegurem o desenvolvimento de uma atividade economicamente produtiva. 
Tabela 1: População Residente de Niterói e Jurujuba

\begin{tabular}{|c|c|c|c|c|c|c|c|c|c|c|c|}
\hline \multirow{3}{*}{$\begin{array}{l}\text { Datas de } \\
\text { referência }\end{array}$} & \multicolumn{8}{|c|}{ POPULAÇÃO } & \multicolumn{3}{|c|}{$\begin{array}{c}\text { TAXA DE } \\
\text { CRESCIMENTO } \\
\text { ANUAL }(\%)\end{array}$} \\
\hline & \multicolumn{2}{|c|}{1970} & \multicolumn{2}{|c|}{1980} & \multicolumn{2}{|c|}{1990} & \multicolumn{2}{|c|}{2000} & \multirow{2}{*}{$70 / 80$} & \multirow{2}{*}{$80 / 91$} & \multirow{2}{*}{$90 / 00$} \\
\hline & $\mathrm{N}$ & $\%$ & $\mathrm{~N}$ & $\%$ & $\mathrm{~N}$ & $\%$ & $\mathrm{~N}$ & $\%$ & & & \\
\hline Niterói & 342.246 & 100,00 & 397.123 & 100,00 & 436.155 & 100,00 & 459.451 & 100,00 & 2,05 & 0,85 & 0,53 \\
\hline Jurujuba & 4.278 & 1,32 & 3.724 & 0,94 & 3.507 & 0,80 & 2.960 & 0,64 & $-1,38$ & $-0,54$ & $-1,56$ \\
\hline
\end{tabular}

Fonte: informações do Instituto Brasileiro de Geografia e Estatística [IBGE]/ Censo Demográfico do Município de Niterói da Secretaria Municipal de Desenvolvimento, Ciência e Tecnologia [CENCITEC]/ Prefeitura Municipal de Niterói (2002, p. 320), compiladas pelas autoras.

Observa-se que o rendimento médio mensal dos chefes de família no bairro de Jurujuba é baixo: $73,78 \%$ possuem renda de até 3 salários mínimos e somente $18,62 \%$ encontram-se na faixa entre 3 e 10 salários mínimos. Entre os mais idosos, há níveis relativamente elevados de analfabetismo (Instituto Virtual Internacional de Mudanças Globais [IVIG]/COPPE/Universidade Federal do Rio de Janeiro [UFRJ], 2002a).

Na Baía de Guanabara há basicamente três tipos de atividades pesqueiras: (i) A pesca artesanal de subsistência, praticada eventualmente por residentes locais, que não são pescadores profissionais e que pescam de forma individual, utilizando instrumentos como a tarrafa e o puçá em embarcações menores. (ii) A pesca artesanal mais organizada e profissional, abrangendo a extração de mexilhão, siri e peixe; emprega barcos maiores e é feita por pescadores que circulam tanto pela Baía como em alto mar. A diferença fundamental em relação à pesca de subsistência é que ela está organizada em colônias de pesca, que comercializam o produto segundo regras próprias. (iii) A pesca industrial, que foge do controle das colônias e que é feita com grandes barcos industriais, muitos deles estrangeiros (Bessa et al., 2004).

O principal objetivo da Associação é garantir a viabilidade econômica de sua atividade, mesmo após a extinção dos métodos tradicionais de extração, devido à transformação socioambiental da Baía de Guanabara. O novo caminho foi implementar um projeto semi-industrial inovador, no qual a perspectiva ambiental foi adicionada à perspectiva econômica já existente, convertendo a maricultura, assim chamada por eles, numa atividade responsável e sustentável. A absorção de conceitos e códigos de gestão ambiental empresarial na maricultura aparece como alternativa para ganho de competitividade e credibilidade da origem da matéria-prima.

Logo após a fundação da Associação, os maricultores buscaram uma nova tecnologia de cultivo de mexilhões, para modificar a atividade extrativa. O método, baseado na utilização de redes de engorda, fez parte do projeto Mexilhão Rio, criado pela Fundação Carlos Chagas Filho de Amparo à Pesquisa do Estado do Rio de Janeiro [FAPERJ] e financiado pelo Fundo Life, do Programa das Nações Unidas para o Desenvolvimento [PNUD]. Esse projeto estava centrado na transferência de tecnologia de cultivo de mexilhões, bem como na construção de um centro de processamento e monitoramento do cultivo na região. A partir de 1993, várias tentativas foram feitas para mudar a tecnologia de cultivo, porém sem sucesso. O projeto acabou dando prioridade à construção do centro de processamento e às atividades nele desenvolvidas, deixando em segundo plano as tentativas de mudar a tecnologia de cultivo, até então precárias.

Muitas tentativas foram feitas para mudar a tecnologia de cultivo, usando-se o sistema long-lines ${ }^{(10)}$; porém, as condições físicas na localidade, na entrada da Baía de Guanabara, não permitiram que a tecnologia resistisse diante das fortes correntes dos canais que desembocam em mar aberto. 
Em resumo, o projeto Mexilhão Rio, que antecedeu o envolvimento do grupo de pesquisa ${ }^{(11)}$, permitiu a construção do Centro de Beneficiamento de Mexilhões e a consolidação da Associação, mas não melhorou a tecnologia de cultivo e de extração. Outro objetivo do projeto era acompanhar o crescimento e a engorda dos mexilhões, por meio de realizações de biometrias mensais, como também avaliar parâmetros relativos do $\mathrm{pH}$, temperatura e salinidade das águas daquela parte da baía. Essas medidas não tiveram êxito no projeto Mexilhão Rio, e só se viabilizariam mais tarde pelo projeto de implantação de um parque de cultivo de mexilhões que contaria com o apoio financeiro da Petrobrás, que será detalhado adiante com a descrição das novas técnicas de cultivo propostas, os métodos de trabalho para a implantação dessas novas técnicas, os embates sobre pontos de vista diferentes em relação a esses métodos e as estratégias empregadas para a absorção de novas condutas e procedimentos baseados na metodologia participativa adotada pela pesquisa.

\section{Método Participativo e Resultados AlCANÇAdos}

Tomou-se como referência metodológica a pesquisa-ação, cujos primeiros registros na literatura acadêmica, de utilização do método, aparecem na obra de Kurt Lewin, nos anos 40, nos Estados Unidos, com abordagem apoiada em pesquisa do tipo experimental. $\mathrm{O}$ emprego desse método ganha espaço no âmbito da abordagem sociotécnica, desenvolvida nos anos 60, na Grã-Bretanha, para o programa de pesquisa no setor de mineração (Vergara, 2006). No Brasil, os primeiros registros de emprego da pesquisa-ação aparecem quase sempre associados a Thiollent, autor que, desde a década de 80 , vem empregando esse método nos seus trabalhos de pesquisa e consultoria em organizações, conforme assinala Vergara (2006).

Para Thiollent (1997), a pesquisa-ação resulta numa ação direta entre pesquisadores e atores sociais em busca de soluções para problemas práticos, o que implica envolvimento entre as partes, onde não há espaço para um posicionamento neutro, sendo que as soluções escolhidas devem chegar a um acerto consensual entre os seus executores. A diferença da pesquisa-ação de outras metodologias de pesquisa é que ela não se limita a evidenciar, descrever e analisar um problema; nela há um compromisso dos atores sociais em prol de melhorias e mudanças, freqüentemente por meio da seleção e resolução de problemas-chave que podem desencadear mudanças maiores na organização da comunidade envolvida (Thiollent, 1997 como citado em Teixeira \& Bessa, 2006).

A adoção da pesquisa-ação como metodologia de trabalho auxiliou nos procedimentos de escolha e criação do parque de cultivo e na reestruturação das formas tradicionais de trabalho do grupo social, conforme demonstrado em artigo de Teixeira e Bessa (2006).

A metodologia participativa não só contribui para mobilizar os atores numa discussão sobre a pertinência das suas questões, como ajuda a elucidar os desdobramentos dessas questões, como a relação, por exemplo, entre os problemas ambientais e as atividades econômicas, antes abordadas de maneira totalmente dissociada. Em trabalho anterior foram apontados os procedimentos adotados entre os pesquisadores e os pescadores que redundaram numa série de ações conjuntas (Teixeira \& Bessa, 2006). O que se comprovou com a pesquisa-ação é que a participação dos atores, tanto pelo lado dos pescadores como dos próprios pesquisadores, é mais dinâmica porque ela coloca em questionamento os métodos tradicionais de produção e trabalho. Conseqüentemente, instiga a busca por novas tecnologias de produção menos agressivas ao meio ambiente e ajuda a organizar formas mais produtivas de trabalho.

No entanto, é preciso ressaltar que essa dinâmica, que implica troca de idéias, não ocorre sem conflitos, espelhando, em última instância, divergências e interesses contrastantes.

Como evidenciam Teixeira e Bessa (2006, p. 110): “o resultado desse compartilhamento de idéias, muitas vezes, gera conflitos reveladores de divergências de interesses, surgimento de novas lideranças, 
induzindo novos encaminhamentos para importantes decisões, colocando em xeque os valores e a cultura dos envolvidos diante da necessidade de mudança".

Uma das manifestações de conflito, mais freqüente na convivência entre os diferentes atores envolvidos com o presente projeto de pesquisa, partia da própria liderança local dos pescadores. A compreensão dessa manifestação requer uma visão crítica da própria fonte de saber técnico. Se, por um lado, a prática dos métodos tradicionais de extração e cultivo transmitidos pelos mais velhos aos mais novos não era totalmente desprezível, no novo aprendizado, no entanto, ela não se tinha mostrado suficiente para alavancar o desenvolvimento da atividade, conforme já se havia comprovado nas formas de cultivo e extração em experiências anteriores ${ }^{(12)}$. Fato em si é revelador da necessidade de aquisição de novos conhecimentos, o que implicava a conflitante aceitação de um saber advindo de fora.

Por outro lado, o saber de fora, apesar de reconhecido como necessário, era visto pelo líder e seus pares como uma ameaça ao domínio deles do saber, que implicava, na verdade, o entendimento de questionamento de poder.

A resistência, portanto, estava contraditoriamente relacionada ao sucesso do parque de cultivo implantado com as inovações tecnológicas trazidas pelos agentes externos. No entanto, cabe a ressalva que essa resistência não era um fator isolado. O convívio de três anos dos pesquisadores na localidade revelou animosidades e conflitos de interesses entre diferentes grupos sociais atuantes na região e a própria liderança local. Ao se comprovar a eficácia dos novos métodos, colocava-se em xeque, por desdobramento, a sustentação de uma liderança que havia sido construída por um saber agora ultrapassado que, embora reconhecesse o valor do novo conhecimento, não queria a presença dos pesquisadores interferindo no seu espaço de poder.

\section{A Definição do Campo Técnico da Atividade Econômica Baseada no Método da Pesquisa-Ação}

Para a escolha do local de cultivo, a área próxima à Fortaleza de Santa Cruz, levou-se em conta os seguintes requisitos: (i) a hidrodinâmica do local, garantindo a renovação da água e condições de abrigo compatíveis com a estrutura de cultivo; (ii) as condições bioecológicas para o cultivo, a profundidade e a compatibilidade com as demais atividades marítimas já existentes (navegação, pesca, recreação); (iii) a inexistência de poluentes, ou existência deles nos limites permitidos pela legislação brasileira, conforme verificação por meio de análises físico-químicas e microbiológicas; (iv) a segurança, no sentido de evitar roubos e danos no cultivo implantado; (v) a conveniência logística por ser de fácil acesso (IVIG/COPPE/UFRJ, 2002b).

A etapa seguinte da pesquisa-ação resultou na implantação da fazenda marinha, com a confecção e instalação dos espinhéis de cultivo, de acordo com uma técnica que aperfeiçoa a anteriormente praticada pelos maricultores. O processo compreendeu diversas atividades realizadas conjuntamente pelos pesquisadores e pelos membros da associação. Estabeleceu-se um compromisso de realizar, pelo menos, um mutirão por semana, para os trabalhos de confecção, instalação e semeadura dos espinhéis de cultivo. Durante os mutirões, os pesquisadores puderam trocar conhecimentos com os maricultores, debatendo a estratégia tecnológica mais adequada, repassando novas técnicas e assimilando a experiência prática e o conhecimento deles. Realizaram-se também oficinas de trabalho, nas quais era debatida a necessidade de novas técnicas de cultivo ${ }^{(13)}$.

Um ponto central da pesquisa-ação implicou a discussão técnica sobre confecção de espinhéis, pois envolvia uma avaliação do método anterior, que se mostrava ineficaz. Os maricultores inicialmente estranharam a nova tecnologia; porém, ao receberem as explicações do porquê de cada opção realizada, acabaram por se convencer de que a nova estrutura minimizaria os riscos de perda. Além disso, com a manutenção e o acompanhamento semanal do cultivo implantado, seria possível verificar o surgimento de problemas e solucioná-los, antes de se tornarem uma ameaça para o cultivo (IVIG/COPPE/UFRJ, 2002b). 
O terceiro problema tratado pela pesquisa-ação envolveu a reestruturação das atividades de beneficiamento e consolidação de mudanças na organização do trabalho nessas atividades. Esperou-se da pesquisa-ação uma melhoria do processo que redundasse num controle de qualidade mais apurado. Foi um trabalho lento e de longo prazo, durante o qual os pesquisadores esboçaram sugestões sobre diversos assuntos que foram amplamente discutidos com os trabalhadores. Os aspectos ergonômicos (sobretudo na tarefa de descarregamento dos barcos), o de reciclagem dos resíduos do processo (aproveitamento na fabricação de tijolos), as tarefas relativas à implantação da nova estrutura para receber o parque de cultivo de mexilhões, a adaptação de um barco para a atividade do cultivo e extração dos mexilhões, o monitoramento contínuo dos mexilhões do parque de cultivo implantado, foram tratados pela abordagem participativa.

Uma proposta mais audaciosa postulou discussões que foram travadas sobre a necessidade de implantação, pela Associação, de um sistema de gestão ambiental, ou melhor, de alguns princípios baseados, por exemplo, na ISO 14001. Além de permitir maior controle do processo de produção e garantir a qualidade do produto final, um sistema de gestão ambiental que pudesse ser adaptado numa escala menor, poderia modificar as relações entre os atores sociais que atuam na região analisada.

Nesta conversão da atividade artesanal em uma produção industrial de pequena escala o uso de um código de conduta empresarial pode diferenciar o processo, por introduzir variáveis ambientais ainda no seu nascimento. Como os maricultores da Enseada de Jurujuba já têm consciência relativa dessas variáveis, a introdução de uma norma de gestão ambiental seria supostamente menos difícil. Além do mais, a certificação estimularia o empresariado a adotar medidas compatíveis com o compartilhamento responsável das águas da Baía de Guanabara. Apenas uma empresa da região, a Brasil Amarras, que não está incluída na tipologia de pescado, obteve o certificado ISO 14001. Por outro lado, o poder público também teria um exemplo a ser usado como jurisprudência quanto ao uso inadequado da baía. Isso, no entanto, poderia ser alavancado, mediante o apoio de futuras parcerias que esses produtores venham a constituir.

\section{CONCLUSÕES}

As ações e os projetos dos pescadores artesanais de Jurujuba somam-se a vários outros casos de pequenos produtores extrativistas que conseguem unir eficiência econômica e preservação ambiental, como, por exemplo, os seringueiros da Amazônia, com seus sistemas de manejo ambiental.

Antes formas aleatórias de trabalho eram consideradas ameaças ao equilíbrio ambiental, pois não consideravam nenhum tipo de preservação na organização da sua atividade econômica. A conseqüência disso era a associação das práticas extrativistas à degradação ambiental, vista a pobreza como estimuladora dessa associação.

Essa hipótese, tão corrente, de vinculação entre pobreza e degradação ambiental, encontra-se hoje aparentemente refutada, pois a tendência mundial tem sido a de estimular políticas de responsabilidade social, fato presente nas empresas, atualmente, que buscam, por meio de alianças estratégicas, o envolvimento de atores, antes excluídos, agora pertencentes ao universo dos stakeholders.

O caso aqui estudado se contrapõe tanto à crença numa plasticidade da natureza, quanto ao temor de que, numa sociedade capitalista, nenhuma atividade econômica possa ser socialmente responsável. Ação social e natureza estão em contínua interação, num verdadeiro processo dialético (Murphy, 1994).

A situação da Baía de Guanabara mostra quanto a industrialização irrefletida pode trazer riscos consideráveis para a própria sociedade moderna. Mas suas águas poluídas provocam efeitos desiguais nas atividades econômicas dos diferentes atores que nela convivem. Apesar dos esforços para se modernizarem, até mesmo por meio de uma combativa Associação, os pescadores artesanais 
encontram-se numa situação histórica de desigualdade e dependência em relação ao empresariado local. Seus próprios esforços são suficientes (até quando?) para garantir a sobrevivência de sua atividade econômica, mas não para fazê-la desenvolver-se de modo sustentável e perene. Daí a necessidade de envolverem-se em movimentos e organizações em prol da recuperação de toda a baía, como foi apontado neste trabalho, comprovando-se assim que a resolução dos riscos causados pela própria modernização passa necessariamente por uma tomada de decisão mais participativa, ou pelo menos negociada, entre os atores envolvidos e não por uma confiança cega em soluções técnicas elaboradas a distância. Tanto a imposição legal quanto os sistemas organizacionais de gestão ambiental são importantes, mas funcionam ainda melhor com o envolvimento das partes interessadas.

Sob estas condições, a relação conflituosa entre produção industrial empresarial e produção artesanal pode acabar gerando uma condição ambiental mais sustentável. No entanto, isso não é tão simples quanto parece. Do lado dos maricultores, há óbvio interesse na preservação ambiental, já que sua atividade só se sustentará desta forma. Do lado das empresas, a percepção da generalização do risco ambiental é bem mais lenta, mas a pressão conjunta do poder público e de outros agentes sociais pode transformar-se num fardo insuportável para as atividades industriais poluidoras e predatórias.

Ao lançarem seu projeto ambiental, os pescadores assumem uma posição de vanguarda na modernização industrial da região. De modo geral, todo empreendimento local organizado, que necessite de bom padrão de qualidade ambiental, exigirá de organizações industriais, tradicionalmente poluidoras, maior controle da disposição e emissão de resíduos. Os insumos ambientais de uma área compartilhada provocam a criação de um mercado de bens naturais, gerando competição entre aqueles que usam esses insumos. Numa região como a Baía de Guanabara, uma vez que os conflitos tenham sido dirigidos para a busca de uma produção industrial mais ecológica, o próprio quadro de dependência e desigualdade na utilização desses bens pode ser revertido, melhorando a qualidade de vida da população e comprovando-se a dimensão social embutida na estratégia tecnológica adotada.

Há, portanto, uma necessidade precípua de integrar estratégias políticas em prol de interesses comuns, ou, pelo menos, que sejam capazes de dirimir os interesses conflitantes, para se alcançar o desenvolvimento econômico local com preservação ambiental.

A análise da experiência relatada neste trabalho mostra que, apesar da vontade dos maricultores de transformar uma atividade extrativista, ilegal, numa atividade produtiva legalmente reconhecida, não se constituiu sem dificuldades e sem conflitos.

Na dialética das relações locais entre os maricultores e os pesquisadores foi visto que a questão do novo saber técnico introduzido não foi absorvido facilmente, revelando que o receio da liderança local de ter o seu poder questionado, em face das inovações técnicas, era maior do que a própria vontade de transformar o quadro produtivo da atividade econômica.

Mesmo com todas as dificuldades apontadas pela análise, o resultado da experiência é avaliado como positivo, uma vez que foi alcançado o objetivo principal proposto pelos pescadores, o de transformar o desenvolvimento da sua atividade econômica sob novos padrões técnicos, legais e ambientais.

\section{Artigo recebido em 22.07.2007. Aprovado em 12.08.2008.}

\section{NOTAS}

\footnotetext{
${ }^{1}$ As reflexões apresentadas neste trabalho decorrem da elaboração e da implantação de um projeto de pesquisa realizada por um grupo de pesquisadores junto a uma comunidade de pescadores localizada às margens da Baía de Guanabara, RJ, que contou com o apoio financeiro da Petrobrás.

${ }^{2}$ São seis as indústrias de pescado de pequeno a grande porte localizadas nos municípios de Niterói e São Gonçalo, às margens da baía.
} 
${ }^{3}$ Cabe ressaltar que as principais indústrias de grande porte na bacia da Baía de Guanabara são a refinaria da Petrobrás, a REDUC, situada no município de Caxias e as multinacionais Bayer e a ex-Ciba Geigy, atualmente chamada Ciba Especialidades Químicas (Scheeffer, 2002, p. 15).

${ }^{4}$ Fundada em 1940, a ABNT corresponde ao Fórum Nacional de Normalização e promove a elaboração de normas em diversos domínios de atividades, além de efetuar a certificação de produtos e sistemas.

${ }^{5}$ Segundo Vinha (2001, p. 178), o termo stakeholders é um termo abrangente, e por isso já foi consagrado na literatura especializada, por incluir, além dos grupos de interesse ou partes interessadas, todos os membros da cadeia produtiva, as comunidades, as ONGs, o setor público e outras firmas e indivíduos formadores de opinião.

${ }^{6}$ Relatos de ganhos tecnológicos e financeiros por grupos locais ligados à atividade extrativa do mexilhão em diferentes partes do Brasil, encontram-se no relatório Gestão Ambiental na Atividade Comunitária de Cultivo, Extração, Beneficiamento e Comercialização de Mexilhões na Baía de Guanabara - Uma Proposta de Transformação da Atividade Artesanal em uma Atividade Industrial da Produção Local, Economicamente Sustentável. Instituto Internacional Virtual de Mudanças Globais (IVIG/COPPE/UFRJ, 2002b).

${ }^{7}$ A produção de esgoto doméstico é da ordem de 2 milhões de metros cúbicos ao dia, correspondente a uma carga orgânica de 465 toneladas ao dia. Desse total, 68 toneladas apenas recebem algum tipo de tratamento antes de serem lançadas na baía (Scheeffer, 2002, pp. 15-17; Amador, 1997).

${ }^{8}$ As indústrias são a Atlantic, Conservas Piracema, Conservas Rubi, a Friduza e a Quaker (Scheeffer, 2002, p. 154).

${ }^{9}$ Os pesquisadores acompanharam os representantes dos pescadores em reuniões junto às Secretarias de Fazenda, de Urbanismo e de Meio Ambiente e Recursos Hídricos do Município de Niterói para se discutir a possibilidade de reativação do Projeto de Melhorias Urbanísticas do Bairro de Jurujuba, Niterói, no período de 2001 a 2003.

${ }^{10}$ Consiste em um sistema utilizado na ostreicultura japonesa, conhecido no Brasil pela denominação de espinhel. Trata-se de um cabo-mestre mantido na superfície por flutuadores e fundeado pelas extremidades através de duas poitas de concreto, âncoras ou garatéias. Ao cabo mestre são fixadas as "cordas de mexilhão" que ficam suspensas na coluna d'água até o momento da colheita. O espinhel pode ser duplo ou simples; o primeiro contém dois cabos mestres dispostos paralelamente (Avelar, 2003).

${ }^{11} \mathrm{O}$ grupo de pesquisa constituiu-se de técnicos oriundos de diversas formações: biologia, engenharia ambiental e química, pedagogia e sociologia.

12 As razões técnicas dos resultados negativos apresentados pelo parque de cultivo implementado inicialmente pelos pescadores, ainda sem a participação dos pesquisadores e os ganhos adquiridos, em termos técnicos, com a presença desses agentes externos, encontram-se no relatório Gestão Ambiental na Atividade Comunitária de Cultivo, Extração, Beneficiamento e Comercialização de Mexilhões na Baía de Guanabara - Uma Proposta de Transformação da Atividade Artesanal em uma Atividade Industrial da Produção Local, Economicamente Sustentável. Instituto Internacional Virtual de Mudanças Globais (IVIG/COPPE/UFRJ, 2002b).

${ }^{13}$ Desenvolveu-se uma nova forma de amarração das bombonas ao cabo mestre do espinhel; foram protegidos os cabos de amarração das bombonas com mangueiras e realizaram-se novas etapas de confecção do cabo mestre do espinhel.

\section{REFERENCIAS BIBLIOGRÁFICAS}

Albrow, M. (1990). Max Weber's construction of social theory. London: Mcmillan.

Amador, E. S. (1997). Baía de Guanabara e ecossistemas periféricos: homem e natureza. Rio de Janeiro: Reproarte Gráfica e Editora Ltda.

Assembléia Legislativa do Estado do Rio de Janeiro. (1998). Comissão permanente do poder legislativo estadual acionará TCE para auditoria do PDBG. Jornal Informativo da Comissão de Meio Ambiente, (7), 4-5.

Avelar, J. C. (2003). Manual de mitilicultura. In Instituto Internacional Virtual de Mudanças Globais/COPPE/Universidade Federal do Rio de Janeiro. Gestão ambiental na atividade comunitária de cultivo, extração, beneficiamento e comercialização de mexilhões na Baía de Guanabara - Uma proposta de transformação da atividade artesanal em uma atividade industrial da produção local, economicamente sustentável. [Documento Anexo ao Relatório Técnico Final do Projeto UFRJ-PETROBRAS 3325b]. Rio de Janeiro: Autores. 
Beck, U. (1994). Risk society - Towards a new modernity. London: Sage.

Bessa, E. S., d'Avignon, A., Valle, R., \& Teixeira, M. G. (2004, September). Integrating economic development and the environment: artisan fishing production in Guanabara Bay, Rio de Janeiro. Environmental Management, 34(3), 332-340.

Bielschowsky, R. (2000). Cinqüenta anos de pensamento na CEPAL. São Paulo: Record.

Catton, W., Jr., \& Dunlap, R. (1978). Environmental sociology: a new paradigm. American Sociologist, 13(1), 41-49.

Confederação Nacional da Indústria/Banco Nacional do Desenvolvimento Econômico e Social/Serviço Brasileiro de Apoio às Micro e Pequenas Empresas. (1998). Pesquisa gestão ambiental na indústria brasileira. Rio de Janeiro: Autores.

Fundação Estadual de Engenharia do Meio Ambiente. (2000). Programa de despoluição da Baía de Guanabara - Ganhos ambientais referentes às 55 indústrias prioritárias (Relatório Técnico). Rio de Janeiro, RJ, Coordenadoria Técnica.

Furtado, C. (2002). Em busca de novo modelo: reflexões sobre a crise contemporânea (2a ed.). São Paulo: Paz e Terra.

Griefahn, M. (1993, July). Initiatives in Lower Saxony to combine the ecology and economy, ecocontrolling, eco-purchasing and EXPO-2000. Proceedings of the Conference 2020 Visions Britain, Germany and a New Environmental Agenda, London, United Kingdom.

Instituto Brasileiro de Geografia e Estatística. (2002). Censo demográfico do município de Niterói da Secretaria Municipal de Desenvolvimento/ Prefeitura Municipal de Niterói. Niterói, RJ: Autor.

Instituto Internacional Virtual de Mudanças Globais/COPPE/Universidade Federal do Rio de Janeiro. (2002a). Gestão ambiental na atividade comunitária de cultivo, extração, beneficiamento e comercialização de mexilhões na Baía de Guanabara - Uma proposta de transformação da atividade artesanal em uma atividade industrial da produção local, economicamente sustentável (Segundo Relatório Técnico do Projeto UFRJ-PETROBRÁS No 3325b). Rio de Janeiro, RJ: Autores.

Instituto Internacional Virtual de Mudanças Globais/COPPE/Universidade Federal do Rio de Janeiro. (2002b). Gestão ambiental na atividade comunitária de cultivo, extração, beneficiamento e comercialização de mexilhões na Baía de Guanabara - Uma proposta de transformação da atividade artesanal em uma atividade industrial da produção local, economicamente sustentável (Terceiro Relatório Técnico do Projeto UFRJ-PETROBRÁ $\mathrm{N}^{\mathrm{o}} 3325 \mathrm{~b}$ ). Rio de Janeiro, RJ: Autores.

Ministério do Meio Ambiente, dos Recursos Hídricos e da Amazônia Legal - Secretaria de Coordenação dos Assuntos de Meio Ambiente. (1997). Diretrizes ambientais para o setor pesqueiro - Diagnóstico e diretrizes para a pesca marítima. Brasília, DF. Recuperado em 28 janeiro, 2001, de http://www.presidencia.gov.br/estrutura_presidencia/seap/pesca/

Murphy, R. (1994). Rationality and nature - A sociological inquiry into a changing relationship. Colorado: Westview Press.

Parker, D., \& Martin, S. (1993). The impact of UK privatization on labour and total factor productivity [Working Papers in Commerce N ${ }^{\circ}$ 24]. London School of Economics, London, UK.

Perrow, C. (1984). Normal accidents: living with high-risk technologies. New York: Basic Books.

Redclift, M. (1984). Development and the environmental crises. London: Methuen. 
Rodríguez, R. G. (2007, novembro). Pueden ser innovadoras las actividades primarias? El caso del cultivo de mejillón en Galícia. Anais do Seminário RedeSist Dez Anos, Rio de Janeiro, RJ, Brasil.

Scheeffer, M. (2002). Uma avaliação do controle industrial do programa de despoluição da Baía de Guanabara: o caso das indústrias prioritárias. Tese de mestrado, Universidade Federal do Rio de Janeiro, RJ, Brasil.

Teixeira, M. G. C,. \& Bessa, E. S. (2006). Dilemas culturais locais na absorção de tecnologias inovadoras. Organizações \& Sociedade, 13(38), 107-118.

Thiollent, M. (1997). Pesquisa-ação nas organizações. São Paulo: Atlas.

Vergara, S. C. (2006). Métodos de pesquisa em administração (2a ed.). São Paulo: Atlas.

Vinha, V. (2003). As empresas e o desenvolvimento sustentável: da eco-eficiência à responsabilidade social corporativa. In P. May, M. C. Lustosa, \& V. Vinha (Orgs.). Economia do meio ambiente (pp.173-196). Rio de Janeiro: Elsevier. 